\title{
УПРАВЛЕНИЕ КАРЬЕРНЫМ ПРОЦЕССОМ В УСЛОВИЯХ РАЗВИТИЯ ПЕРСОНАЛА СОВРЕМЕННОЙ ОРГАНИЗАЦИИ
}

\section{(c) 2021 Иванова Наталия Александровна}

кандидат экономических наук, доцент, кафедра «Экономика высокотехнологичных производств» Санкт-Петербургская государственная академия аэрокосмического приборостроения, Россия,

Санкт-Петербург

E-mail: prekrasnova.v@mail.ru

Актуальность статьи обусловлена вопросами карьерного роста в организациях, развивающихся в соответствии с глобальными экономическими и технологическими тенденциями. В последние годы этот процесс заметно интенсифицируется, что связано с возрастающим значением управления карьерным процессом как важнейшего фактора повышения эффективности в новых условиях хозяйствования. Ведущим подходом к исследованию данной проблемы явилось изучение мотивации и стимулирования личности, анализа профессиональной карьеры личности как важнейшего экономического компонента успешной деятельности организации.

Ключевые слова: карьера, карьерный рост, управление картерным процессом, мотивация, стимулирование личности.

В науке управление человеческим капиталом, карьера определяется как некая последовательность событий, связанных с работой определенного лица в одной или нескольких организациях (Baruch Y., Greenhaus J.H., Callagan G. A.).

В соответствии с современной трактовкой карьера включает в себя не только вертикальное продвижение на более высокие должности, но и любое изменение должностей, обязанностей и связанное с этим стремление к обучению и приобретению ценного опыта необходимых для работы.

В настоящее время большинство ученых в сфере управления человеческим капиталом признали, что карьера по своей природе принадлежит личности, однако при этом организации через свои системы развития карьеры могут активно участвовать в развитии карьеры сотрудников.

Необходимо отметить, что теория развития карьеры обязана своему становлению и развитию исследованиям в сфере карьерных циклов (этапов). Изучением этапов карьеры человека (его жизненных циклов) занимались исследователи в области психологии (организационной психологии), социологии, менеджмента и других научных дисциплин. Сегодня на современном этапе существуют различные взгляды на количество этапов карьеры и их качественную характеристику [1].

Основателями теории карьерных этапов

считают Д. Миллера, В. Форма, Э. Гинзбурга. При этом большая работа в сфере карьерного развития была сделана американским исследователем С.Осиповым («Теория развития карьеры»). Большую популярность среди исследователей карьерных этапов имеют труды Э.Шейна и Д. Сьюпера. Можно еще перечислить таких авторов, как Д.Гринхаус, Д. Левинсон, Р.Пек, У.Слокум, С.Сиарс, С.Шартл, Э.Эриксон. Также можно отметить работы: Э.Воутилайнен, Г.Перри, Т. Санталайнен, Д. Фонтана.

В настоящее время во многих странах (США, Великобритания, Финляндия, Канада) теория развития карьеры обретает статус академической дисциплины. Большой вклад в этом вопросе был внесен Д. Т. Холлом [2].

Д. Миллер считает, что успех в карьере зависит от уровня заработной платы и продвижения по служебной лестнице (иерархии организации). Это был «классический» взгляд на вертикальное внутриорганизационное развитие карьеры.

B дальнейшем исследования Д.Миллера, В. Форма и Э. Гинзбурга были развиты американским исследователем - психологом Дональдом Сьюпером. При этом периодизация Д. Сьюпера касательно карьерных этапов человека получила широкую популярность в западной доктрине.

Этапы карьерного пути отражают присущую традиционной концепции периодизацию карьеры. Сегодняшняя организационная среда имеет динамичный характер в силу того, что происхо- 
дит сокращение количества времени, необходимого для определенного технологического цикла.

Во второй половине 70-х годов прошлого столетия американский исследователь Д. Т. Холл в своей работе «Карьера в организациях» представил новый взгляд на развитие карьеры человека.

В 90-е годы XX века Д. Холл совместно с другим исследователем Ф.Мирвисом предпринял попытку пересмотреть прежнюю концепцию, где карьера рассматривалась как линейнопоследовательное перемещение от нижней ступени организации к более высоким, что соответственно вполне прогнозируема и удобна в части определения конкретных стадий (работs Далтона, Томпсона, Прайса в 1977 году).

Они предложили более усложненный и динамичный характер для карьерного роста сотрудника в современных организациях. Концепция получила название «поливариативная карьера». Указанная карьера включает в себя различные характерные динамики современной организации (подъемы, спады, возврат к предыдущей позиции, переводы на аналогичные уровни и даже замену одного вида деятельности другим).

Авторы доказывают, что успешность карьеры не должна оцениваться старым, традиционным методом, когда успех/неуспех определяется наличием или отсутствием роста по карьерной лестнице. Каждый сотрудник имеет свой уникальный путь и здесь успешность карьеры можно рассмотреть путем оценки совокупности всех ситуаций реализованного выбора сотрудника, то есть там, где по традиционному взгляду на развитие карьеры можуј увидеть неудачу.

Д. Холл и Ф. Мирвис в своих работах предлагают увидеть успешность карьеры в зависимости от субъективного осознания наличия данного успеха человеком, то есть нельзя отбрасывать назад «психологический успех» и зацикливаться на внешних знаках и отметках.

В конце 80-х годов XX века Д.Иванцевич и М.Матесон предложили самостоятельное понятие «стрессоры карьерных возможностей». По их мнению, в организационной среде существуют аспекты, которые могут влиять на субъективное осознание личности карьерного роста. Считается, что если в ходе построения карьеры человек впадает в состояние тревоги и фрустрации, то карьера является стрессовой и становится проблематичной. Так, к примеру, возможна ситуа- ция, когда работник недоволен своей позицией в организации, чувствует неудовлетворенность карьерными ожиданиями.

М.Драйвером, К. Бруссо и К. Энеротом были разработаны типологии карьеры, определенные как линейная, экспертная, спиральная и переходная [3].

Так, линейная карьера представляет собой вертикальное движение, с целью достижения пика в иерархии организации. В указанной карьере человек имеет потребность во власти, управлении другими людьми.

Экспертная карьера строится с целью профессионального развития, когда человек имеет потребность в расширении своих профессиональных навыков и удовлетворен стабильным положением.

Спиральная карьера подразумевает смену циклов в карьере, которые, по мнению авторов длятся около 7 лет. Каждый цикл связан с личным творческим развитием человека.

Последний вид - переходный, характеризуется изменением вида деятельности в карьерном пути человека и прежде всего связан со стремлением работника к независимости и разнообразию.

М.Савицкас считает, что большинство теорий в области карьерного развития ставили задачу по решению карьерного роста человека внутри определенной организации. Таким образом, по его мнению, сформировалась некая модель, именуемая как «модель развития призвания».

Новый исторический период и изменения в сфере управления заложили основу для рождения новой концепции индивидуальной карьеры. В этом контексте М.Артур и Д.Руссо использовали концепцию «безграничной карьеры», М.Пейперли и Ю.Барух говорили о «посткорпоративной карьере», Д.Пинк утверждал, что современная карьеру можно обозначить как «Лего карьера», так как современные сотрудники должны строить и реконструировать свою карьеру из отдельных частей. Этими частями называются потребности, способности, возможности, контракты и т.д.

В науке управления человеческими ресурсами карьера определяется как последовательное продвижение в работе в одной или нескольких организациях в целях приобретения опыта человеком.

В соответствии с рядом современных кон- 
цепций карьера включает не только вертикальное продвижение на более высокие должности, но и любое изменение должностного положения, обязанностей, обучение, которые связаны со стремлением приобрести различный опыт работы.

В настоящее время большинство исследователей пришли к общему пониманию того, что «карьера» как понятие охватывает не только личность, но и организацию, которая с помощью своей системы планирования карьерного роста может принимать активное участие в развитии карьеры своих работников.

На сегодняшний день в связи с большим количеством исследований в сфере карьерного развития имеется большое количество определений понятия «карьера».

Если посмотреть специальную литературу в области управления персоналом и карьерой то можно отметить, что термин «карьера» понимается в двух значениях.

Первое, карьера как стремление к чему-либо, то есть процесс, а во-вторых, как результат того, к чему стремился человек. Так, ряд исследователей в области управления организацией определяют карьеру как поэтапное занятие определенных должностей конкретным сотрудником, то есть дают более сжатое и емкое определение. В то же время другие авторы утверждают, что карьера есть некий личностный взгляд человека на свою позицию и поведение в связи с накоплением опыта и увеличением человеческого капитала в процессе профессиональной практики. Данное определение выделяет «субъективное осознание» человеком своего профессионального пути.

Используется ряд различных ключевых слов при определении понятия карьеры. Сюда можно отнести такие слова, как мобильность, перемещение, продвижение, рост.

Мобильность можно определить, как возможность человека менять свое положение, социальный статус в обществе. Карьерная мобильность определяет возможности сотрудника к должностным перемещениям. Само слово перемещение является более широким понятием и обозначает территориально-пространственное передвижение [4].

Таким образом можно отметить, что карьера как явление многообразное и сложное, в связи с чем для ее полного исследования необходимо изучить ее виды, характеристику, а также раз- личные подходы к расчленению типологии карьеры.

Многие исследователи условно делят карьеру на вертикальную, обозначаемую как служебное продвижение и горизонтальную, которая подразумевает профессиональное развитие сотрудника.

Кроме горизонтальной карьеры и вертикальной выделяют ступенчатую и центростремительную.

Ступенчатая карьера понимается как комбинация двух видов карьер:

- горизонтальной;

- вертикальной.

Это значит, что продвижение карьеры сотрудника в определенный момент времени может происходить горизонтальным путем, когда он перемещается в другую функциональную область деятельности, где расширяются и усложняются задачи в отличие от прежней позиции и соответственно работник набирает опыта в профессиональной сфере. После этого происходит вертикальный карьерный рост. Такой вид карьеры дает определенный эффект, так как уже на более высокой позиции сотрудник, имея профессиональный опыт на разных позициях возглавляемого им структурного подразделения, будет принимать более правильное управленческое решение.

Центростремительная карьера обозначает движение к центру управления (организации). В указанном виде карьеры работник может участвовать в различных видах мероприятий (совещание, заседания, конференция и т.п.), которые ранее были для него и для его коллег недоступными, а также иметь определенный доступ в организации к важным информациям, иметь уважение и авторитет у первых руководителей и коллег, получать особо важные поручения от руководства, иметь доверительные отношения с ними и т.п.

Следует отметить, что центростремительная карьера может комбинировать с горизонтальной, то есть сотрудник параллельно с перемещением на другую позицию, с изменением функциональных обязанностей получает возможность напрямую работать с первым руководителем организации как эксперт в определенной области, возникают доверительные отношения с ним и т.П.

В некоторых странах Европы большой популярностью пользуется горизонтальный карьер- 
ный рост, когда сотрудник в процессе горизонтального перемещения на должности становится профессиональным экспертом в определенной сфере (соответственно возрастает уровень заработной платы, авторитет среди коллег и начальства, происходит повышение самооценки и т.п.

Дятлов В.А., Иванов В.Ю., Травин В. В. делят карьеру на два основных вида:

- профессиональную;

- внутриорганизационную.

Под первым видом они понимают процесс, который воспитывает личность как профессионала путем овладения им навыками и опытом в определенной сфере человеческой деятельности. Профессиональная карьера отличается тем, что она отражает процесс прохождения работника через различные стадии профессионального развития.

Второй основной вид карьеры указывает на стадии и особенности развития личности в какой-либо организации. Соответственно, внутриорганизационная карьера в дальнейшем подразделяется на другие подвиды.

C развитием управления карьерными процессами возникли задачи по эффективному управлению карьеры и его планированием. В рамках этой задачи возникла необходимость во взаимодействии этих двух видов карьеры профессиональной и внутриорганизационной.

Необходимо понимать, что изучение этапов карьеры очень важно в сфере планирования карьерного роста сотрудника, так как это позволяет более эффективно строить его карьерную стратегию (карьерный план) в связи с тем, что позволяет правильно подбирать карьерные ступени к жизненным циклам в силу их взаимосвязи и взаимозависимости.

В настоящее время в научной литературе существуют множество определений понятия «планирование карьеры». Многие сходятся во мнении, что планирование карьеры есть процесс взаимодействия организации и работника, направленный на карьерное и профессиональное развитие последнего.

Существуют четыре подхода в определении указанного понятия:

- применительно к отдельному сотруднику;

- относительно организации;

- в отношении организации и сотрудника;

- раскрывающий содержание карьеры.

Планирование карьеры является процессом, включающим в себя определенные цели и за- дачи, направленные на карьерное развитие сотрудника. Карьерное развитие состоит из путей, то есть из чередующихся должностных позиций, на которых необходимо поработать, прежде чем занять определенную в карьерном плане должность.

Так, карьерный путь включает в себя различный арсенал средств, требуемых для нужной квалификации. Это может быть обучение, стажировка или другие средства [5].

Вырупаева Т.В. обозначает планирование профессиональной карьеры как процесс, в ходе которого происходит соизмерение потенциальных возможностей, способностей и целей работника с существующими требованиями организации. Данный процесс оформляется в виде карьерного плана, который предусматривает профессионально-должностное развитие персонала.

По мнению исследователя, указанное планирование ориентировано на:

- изучение последовательности возможного занятия должностной позиции в организации;

- нахождение направлений по развитию сотрудника путем подготовки и повышения квалификации;

- проведение постоянной оценки сотрудника на качество его профессиональной деятельности.

В рамках рассмотрения планирования карьеры необходимо проанализировать термин «развитие карьеры». По мнению ряда исследователей, «развитие карьеры» - это комплекс действий человека по реализации своего карьерного плана. Для развития карьеры сотрудника необходимо ее планирование и управление.

В области экономики термин «управление карьерой» имеет различное толкование. Одно из распространенных взглядов на данное определение заключается в том, что оно понимается как принятая организацией программа по карьерному развитию сотрудника, которая способствует раскрытию его талантов и дальнейшему их развитию и наилучшему применению с точки зрения самой организации

Таким образом, системное планирование карьерное роста включает в себя управление карьерой, так как охватывает такие процессы, как организация карьерного плана, использование мотивационных механизмов для достижения планируемых карьерных задач, контроль за ис- 
полнением и эффективной реализацией карьерного плана.

Исходя из вышеизложенного, под системным планированием карьерного роста следует понимать процесс, основанный на системе ориентированный на определение этапов должностного перемещения, а также профессионального развития сотрудника.

\section{Библиографический список}

1 Лисов В.И. Совершенствование управления кадровым потенциалом // Менеджмент и бизнесадминистрирование. - 2019. - № 1. - С. 122-153.

2 Хомутинникова Т.В.Управление кадровым потенциалом: учебное пособие. - М.: МГУТУ, 2012. - 209 с.

3 Носкова М.В. Теоретическая модель развития экономической категории «кадровый потенциал» // Вестник Алтайского государственного аграрного университета. - 2016. - № 2. - С. 89-93.

4 Прихач А. Активная инновационная деятельность персонала как конкурентное преимущество // Управление персоналом. - 2015. - № 1-2. - С.69.

5 Майбуров И.А. Вклад человеческого капитала в экономическое развитие России // Экономическая наука современной России. - 2016. - № 4. - С. 54-69. 